\title{
Coriander Seed Extract ( Coriandum Sativum L ) As An Antioxidant
}

\author{
Irza Haicha Pratama ${ }^{1}$, Ermi Girsang ${ }^{2 *}$, Tan Suyono ${ }^{3}$ \\ ${ }^{1,2,3}$ Faculty of Medicine, Universitas Prima Indonesia \\ * Corresponding author: \\ Email: ermigirsang@unprimdn.ac.id
}

\begin{abstract}
Diabetes mellitus (DM) is a disease characterized by hyperglycemia, lipoprotein abnormalities, increased basal metabolic rate, enzyme deficiency, and high oxidative stress. This research is an experimental study that aims to explore coriander seed extract (Coriandrum sativum L) using Post-Test Only Control Group Design. This study to was conducted to see the antioxidant potential (DPPH, ABTS, LC-MS/MS) of coriander seed extract (Coriandrum sativum L). Based on the test results, coriander seed extract contains very high phytochemicals, one of which is alkaloid compounds, and in vitro test results found DPPH antioxidant with an average IC50 value of 14.33 $\mathrm{g} / \mathrm{mL}$ and at the lowest concentration $(6.25 \mathrm{~g} / \mathrm{mL}) . \mathrm{g} / \mathrm{mL})$, CSE also showed the highest antioxidant activity against ABTS trapping with an average IC50 value of $74.07 \mathrm{~g} / \mathrm{mL}$ and the results of $L C-M S / M S$ obtained samples of coriander extract containing $0.00009 \%$ chlorogenic acid and quercetin compounds. of $0.00012 \%$.
\end{abstract}

Keywords: Diabetes mellitus, Coriandrum sativum L, DPPH, ABTS, LC-MS/MS

\section{INTRODUCTION}

Diabetes mellitus is a state of hyperglycemia caused by abnormalities in the metabolism of carbohydrates, fats and proteins in the body. This situation can occur due to disturbances in insulin such as lack of insulin production and decreased insulin sensitivity. Symptoms of diabetes mellitus include eating a lot, drinking a lot, urinating frequently at night, and getting tired easily.According to the International Diabetes Federation (2017), people with diabetes mellitus in the world aged 20 to 79 years amounted to 425 million people and is expected to increase in 2045 to 629 million people. Indonesia ranks 6th in the world after China, India, the United States, Brazil, and Mexico with 10.3 million sufferers, it is also estimated that in 2045 it will increase to 16.7 million people. According to Riskesdas 2018, the prevalence of diabetes mellitus in Indonesia continues to increase. This is evidenced by the increase in prevalence from $6.9 \%$ in 2013 to $8.5 \%$ in 2018. Diabetes mellitus (DM) is characterized by hyperglycemia, lipoprotein abnormalities, increased basal metabolic rate, enzyme deficiency, and high stress. Oxidative stress is a condition caused by increased production of free radicals or reduced antioxidant defense activity or both. In connection with this condition, it is known as Reactive Oxygen Species (ROS). There are compounds that are free radicals and some are called non-radical compounds.

Called free radicals if they consist of unstable and reactive molecules that can attack other macromolecules such as lipids, carbohydrates, proteins and nucleic acids. It produces a broad spectrum of oxidative stress on the molecular and cellular mechanisms of various diseases found in humans.Oxidative stress conditions caused by hyperglycemia in diabetes mellitus are generally associated with increased endothelial cell apoptosis in vitro and in vivo as evidenced by various studies showing increased free radical formation and decreased antioxidant capacity. The mechanism of ROS in causing tissue damage under hyperglycemic conditions is accelerated by four important molecular mechanisms, namely activation of protein kinase $\mathrm{C}$ (PKC), increased hexosamine pathway, increased glycation end product (AGE), and increased polyol pathway.Administration of antioxidants is an attempt to inhibit the production of intracellular free radicals or increase the ability of defense enzymes against free radicals to prevent the emergence of diabetes-related oxidative stress and research related to herbal medicines has now become a research topic that has been widely studied to treat complications due to diabetes because herbal medicines have the potential high antioxidants. Coriandum sativum L. or coriander is a common spice used in Indonesia. C. sativum has various bioactive components such as flavonoids, terpenoids, polyphenols which 
act as their therapeutic action. C. sativum is also known to have various pharmacological activities such as antioxidant, antidiabetic and antidyslipidemic.

\section{METHODS}

This research is an experimental study that aims to explore Coriander Seed Extract (C. sativum) as an antioxidant agent using Post-Test Only Control Group Design. This research was conducted in vitro using coriander seed extract.

\section{RESULT AND DISCUSSION \\ In Vitro Test Results \\ DPPH Antioxidant Test Results (2,2-diphenyl-1-picrylhydrazyl-hydrate)}

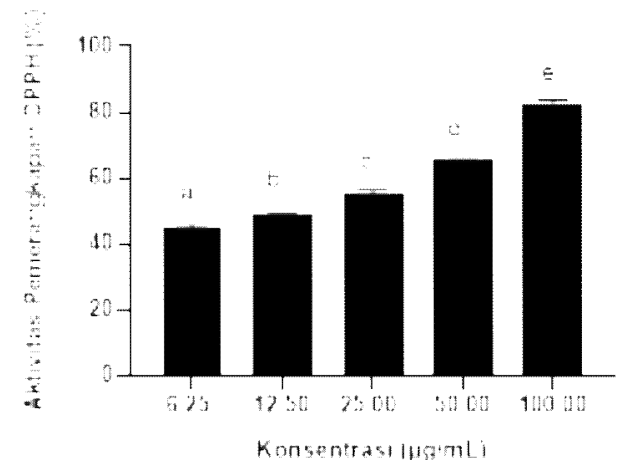

Fig 1. Effect of Grape Extract on DPPH . Antioxidant Activity

*Data are presented in mean \pm SD. Differences in superscript signs $(a, b, c, d, e)$ showed significant differences $(\mathrm{p}<0.05)$ Tukey HSD post hoc test

Based on the measurement results, it can be seen that the antioxidant activity of EBK in DPPH increased along with the decrease in extract concentration. At the lowest concentration $(6.25 \mathrm{~g} / \mathrm{mL})$, EBK showed the highest antioxidant activity against DPPH traps with an average IC50 value of $14.33 \mathrm{~g} / \mathrm{mL}$. These results indicate that EBK has antioxidant activity against DPPH radicals.

\section{ABTS Antioxidant Test Results (2,2'-Azinobis(3-Ethylbenzthiazoline-6-Sulfonate))}

Antioxidant compounds will react with ABTS radicals (2,2'-Azinobis(3-Ethylbenzthiazoline-6Sulfonate)) and reduce the blue-green color formed in ABTS solution by donating hydrogen atoms. ABTS solution is obtained from the reaction between strong oxidizing agents such as potassium permanganate or potassium persulfate with ABTS salts. The color change was measured at a wavelength of $745 \mathrm{~nm}$. The results of the measurement of the percentage of trapping activity and the IC . value ${ }_{50}$ from EBK can be seen in table 2 and presented in Figure 2

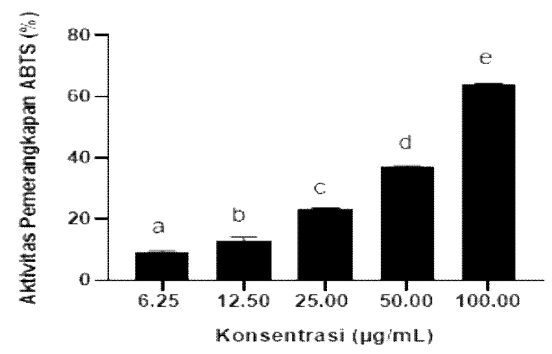

Fig 2. Effect of Coriander Seed Extract on Antioxidant Activity of ABTS

Figure $2.3 *$ Data are presented in mean \pm SD. Different superscript marks (a, b, c, d, e) showed significant differences $(p<0.05)$ Tukey HSD post hoc test.

The antioxidant activity of Coriander Seed Extract in ABTS increases along with the decreased concentration of the extract. At the lowest concentration $(6.25 \mu \mathrm{g} / \mathrm{mL})$, the Coriander Seed Extract showed the highest antioxidant activity against abts with an average IC50 value of $74.07 \mu \mathrm{g} / \mathrm{mL}$. 


\section{Coriander Seed Extract LC-MS/MS Test Results}

LC separates the components of compounds in the sample based on their relative interactions with the stationary phase and the elution of the solvent through the column (mobile phase). The advantage of LCMS is that it can analyze a wider range of components, such as thermally labile compounds, high polarity or high molecular mass, and even proteins. The standard chromatogram of coriander seed extract is shown in Figure 1.

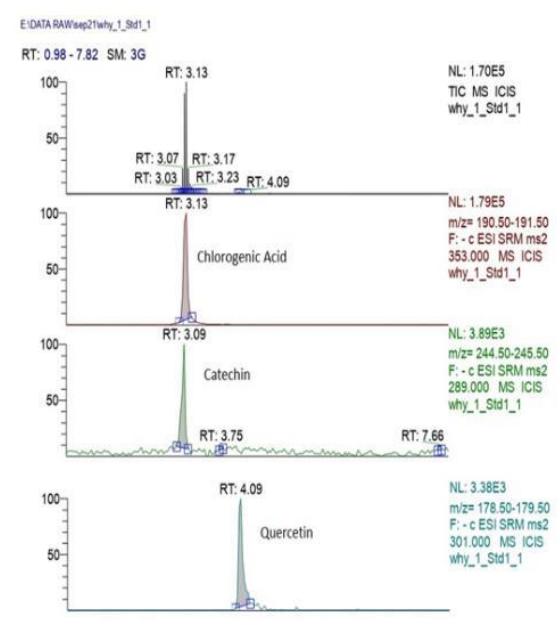

Fig 3. Standard Chromatogram of Coriander Seed Extract

TIC or total ion chromatogram is a combined chromatogram of standard mixtures (chlorogenic acid, catechins, and quercetin). Different compounds will give peaks at different retention times so that their presence in the mixture can be identified. In Figure 2, the standard mixture of chlorogenic acid 1 is identified at RT (Retention Time) 3.13, catechins at 3.09, and quercetin at 4.09. While in Figure 2. shows that in coriander extract chlorogenic acid was identified at RT (Retention Time) 3.13 and quercetin at 4.09, while catechins were not identified.

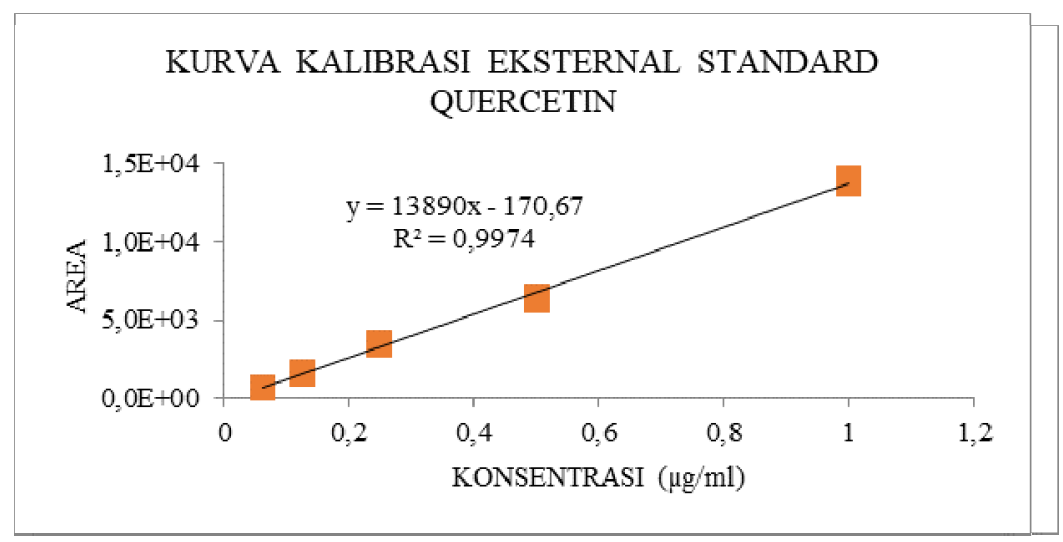

Fig 2. Quercetin . Standard Curve

Based on the results obtained, it can be concluded that the samples of coriander extract contained chlorogenic acid compounds of $0.00009 \%$ and quercetin compounds of $0.00012 \%$. Mass spectrophotometry (MS) is an analytical technique used to determine the presence of compounds based on their molecular weight. The working principle used is the bombardment of organic compound molecules with electron beams so that these compounds can be ionized. The magnetic field will bend the ion so that its molecular weight can be determined. The charge induced when the ions hit the surface will be calculated by the detector in terms of the mass-to-charge ratio $(\mathrm{m} / \mathrm{z})$. The results showed that EBK contained several compounds as shown in Table 2. EBK contained pinobaksin-3-o-phenylpropionate, apigenin-o-rutinoside, and quercetin dimethyl ether-3-o-rutinoside compounds. 
Table 1. Identification of Coriander Seed Extract Target Compounds with ESI-MS

\begin{tabular}{|l|c|c|}
\hline Coriander seeds & MW (g/mol) & MS [MH]- (m/z) \\
\hline $\begin{array}{l}\text { Pinobaksin-3-o- } \\
\text { phenylpropionate }\end{array}$ & 404.25 & 403.274 \\
\hline Apigenin-o-rutinoside & 578 & 577,822 \\
\hline $\begin{array}{l}\text { Quercetin dimethyl ether- } \\
\text { 3-o-rutinoside }\end{array}$ & 638 & 637,490 \\
\hline
\end{tabular}

\section{CONCLUSION}

1. The antioxidant activity of Coriander Seed Extract in DPPH increased along with the decrease in extract concentration. At the lowest concentration $(6.25 \mathrm{~g} / \mathrm{mL})$, Coriander Seed Extract showed the highest antioxidant activity against DPPH traps with an average IC50 value of $14.33 \mathrm{~g} / \mathrm{mL}$. These results indicate that Coriander Seed Extract has antioxidant activity against DPPH radicals.

2. The antioxidant activity of Coriander Seed Extract in ABTS increases along with the decreased concentration of the extract. At the lowest concentration $(6.25 \mu \mathrm{g} / \mathrm{mL})$, the Coriander Seed Extract showed the highest antioxidant activity against abts with an average IC50 value of $74.07 \mu \mathrm{g} / \mathrm{mL}$.

3. LC-MS/MS results obtained by Coriander Seed Extract contained pinobaksin-3-o-phenylpropionate, apigenin-o-rutinoside, and quercetin dimethyl ether-3-o-rutinoside compounds.

\section{ACKNOWLEDGEMENT}

Thank you to the author's family, the academic community of Prima Indonesia University and all parties who participated in helping the author in carrying out the research.

\section{REFERENCES}

[1] Anusooriya, P., Malrvizhi, D., Gopalakrishnan, VK, and Devaki, K. (2014). Antioxidant and antidiabetic effects of the juicy fruit extract of Passiflora ligularis Juss. in streptozotocin-induced diabetic rats. International Scientific Research Notice.http://dx.doi.org/10.1155/2014/130342

[2] Tonneijck, L., Muskiet, MHA, Smits, MM, van Bommel, EJ, Heerpsink, HJL, van Raalte, DH, and Joles, JA (2017). Glomerular hyperfiltration in diabetes: mechanisms, clinical significance, and treatment. J.Am.Soc.Nephrol; 28(4): 1023-39. Doi:10.1681/ASN.2016060666

[3] Sadikot D, Cho P, Joses C,. (2017). IDF Diabetes Atlas. IDF. 8th edition. UK : International Diabetes Federation; P. 1150.

[4] Chen, HW, Yang MY, Hung, TW, Chang, YC, Wang, CJ (2019). Nelumbo nucifera leaf extract attenuated the pathological development of diabetic nephropathy in diabetic rats fed a high-fat diet and streptozotocin. Journal of Food and Drug Analysis; 27(2019): 736-748. Doi: 10.1016/j.jfda.2018.12.009

[5] Omodanisi, EI, Aboua, YG, and Oguntibeju, OO (2017). Assessment of anti-hyperglycemic, anti-inflammatory, and antioxidant activities in methanolic extract of Moringa oleifera in diabetic-induced nephrotosis male Wistar rats. Molecule. 22:439. Doi:10.3390/molecule22040439

[6] Kajal, A. and Singh, R. (2019). Coriandum sativum seed extract reduced the development of diabetic nephropathy in experimental rats through inhibition of AGEs. PLoS One. 14(3): e0213147. Doi: 10.1371/journal.pone.0213147

[7] Reidy, K., Kang, HM, Hostetter, T., Susztak, K. (2014). Molecular mechanisms of diabetic kidney disease. J.Clin.Invest. 124(6): 2333-2340. Doi: 10.1172/JCI72271

[8] Sun, J., Wang, Y., Cui, W., Lou, Y., Sun, G., Zhang, D., et al. (2017). The role of epigenetic histone modifications in diabetic kidney disease involving renal fibrosis. J. Diabetes. Res., 2017: 7242384. Doi:10.1155/2017/7242384

[9] Lin, CF, Kue, YT, Chen, TY, Chien, CT (2016). Quercetin-rich guava juice (Psidium guajava) in combination with trehalose reduces autophagy formation, apoptosis, and pyroptosis in the kidneys and pancreas of type II diabetic rats. Molecule. 21:334. Doi:10.3390/molecule21030334

[10] Al-Snafi, PDAE.2016.'A review on chemical constituents and pharmacological activities of Coriandrum sativum', IOSR Journal of Pharmacy (IOSRPHR), 06(07), pp. 17-42. doi: 10.9790/3013-067031742. 
[11] Anioke, I. et al. 2017. 'Investigation into hypoglycemic, antihyperlipidemic, and renoprotective potentials of dennettia tripetala (Pepper Fruit) seed in a rat model of diabetes', BioMed Research International, 2017. doi: 10.1155/2017/6923629.

[12] Ardiani, R. 2017. 'Anticholesterol Effects of African Leaf Ethanol Extract (Vernonia amygdalina Del.) on Rats', Journal of Mathematics and Natural Sciences Educational Research, 2(1), pp. 153-158

[13] Lin, CF et al.2018.'Epidemiology of Dyslipidemia in the Asia Pacific Region', International Journal of Gerontology, 12(1), pp. 2-6. doi: 10.1016/j.ijge.2018.02.010

[14] G. Vijay Kumar, ND 2016.'Antihyperlipidemic Activity of Leaf', 2016(3), pp. 408-413

[15] Dewi Andang Prastika and Sugita 2018. 'Effectiveness of Coriander Seed Soak (Coriandrum sativum L) for Treatment of Leucorrhoea Problems in Women of Childbearing Age', Integrated Journal of Health Sciences, $7(1)$

[16] Artha, C., Mustika, A. and Sulistyawati, SW 2017. 'Effect of Singawalang Leaf Extract on LDL Levels in Hypercholesterolemic Male White Rats', E-Journal of Indonesian Medicine, 5(2), pp. 105-109. doi: 10.23886/ejki.5.7151

[17] S. Bhat, P. Kaushal, MK and HKS2014. 'Coriander (Coriandrum sativum L.): Processing, nutritional and functional aspects', African Journal of Plant Science, 8(1), pp. 25-33. doi:10.5897/ajps2013.1118.

[18] Yunarto, N., Elya, B. and Konadi, L. 2015. Potential of Ethyl Acetate Fraction of Gambir Leaf Extract (Uncaria gambir Roxb.) as Antihyperlipidemia Potency of Ethyl Acetate Fraction of Gambier Leaves Extract Abstract containing catechins is gambir These tools and materials are rotary evaporator ( Buchi )', Indonesian Pharmaceutical Journal, 5(1), pp. 1-10

[19] Gray, A., Flatt, 1999. Insulin-Releasing And Insulin-Like Activity Of The Traditional Anti-Diabetic Plant Coriandrum sativum (Coriander). Cambridge University Press 81

[20] Foster DW. Diabetes mellitus. In: Isselbacher KJ, Braunwald E, Wilson JD, Martin JB, Fauci AS, Kasper DL, eds. Harrison principles of internal medicine. edition 13. Translated: Asdie AH. Jakarta: EGC, 2000; 5: 2196217. 